\title{
Solitary extramedullary plasmacytoma of the palpebral conjunctiva
}

\author{
JOHANNA M. SEDDON, ' JOEL M. CORWIN, ${ }^{2}$ JOHN J. WEITER, ${ }^{2}$ \\ JANE U. BRISBANE, ${ }^{3}$ AND FRANCIS C. SUTULA ${ }^{1}$
}

From the ${ }^{1}$ Department of Ophthalmology, Tufts-New England Medical Center, ${ }^{2}$ Eye Research Institute of Retina Foundation, and ${ }^{3}$ Department of Pathology, Boston VA Medical Center, Boston, Massachusetts, USA

SUMMARY A 63-year-old man had a solitary extramedullary plasmacytoma of the conjunctiva for several years with no history of ocular inflammation or systemic abnormalities. Immunoperoxidase staining was consistent with a neoplastic lesion. This is the only well documented such case in the recent literature to the best of our knowledge. This rare condition is contrasted with reactive plasma cell granuloma, a benign inflammatory condition, which comprises most of the cases previously reported as plasmacytomas. Since extraskeletal plasmacytomas may be the first manifestation of multiple myeloma, these patients deserve appropriate diagnostic evaluation and close follow-up.

Plasma cell tumours of the conjunctiva are uncommon. When first described in the early twentieth century they were referred to as plasmacytomas or plasmomas. ${ }^{1-8}$ By today's criteria, however, most of these tumours would not be considered true plasmacytomas (rare neoplastic growths consisting of plasma cells) but benign reactive plasma cell granulomas secondary to inflammation. ${ }^{910}$ True plasmacytomas are rare; they occur most frequently in the upper respiratory tract. ${ }^{11}$ An extramedullary plasmacytoma can occur as an isolated lesion or as a manifestation of systemic multiple myeloma. To the best of our knowledge this is the only well documented case of solitary extramedullary plasmacytoma of the conjunctiva in the recent literature.

\section{Case report}

A 63-year-old man was first seen by us in September 1978. He had had adult-onset diabetes mellitus for 16 years and was referred by the medical clinic for an ocular examination. He mentioned that he had had a painless 'growth' on his right lower lid for several years and that it had increased only slightly in size. He had also noted decreasing visual acuity in the right eye for a few years. There was no complaint of ocular

Correspondence to John J. Weiter, MD, Eye Research Institute, 20 Staniford Street, Boston, MA 02114, USA.

Dr. Seddon is currently at the Massachusetts Eye and Ear Infirmary, Boston, Mass. pain, tenderness, or discharge and no history of ocular inflammation or trauma.

On ophthalmological examination his visual acuity was $6 / 60(20 / 200)$ in the right eye and $6 / 24(20 / 80)$ in the left. The middle of the right lower lid was notably swollen. When the lid was everted, a discrete reddishtan mass measuring $16 \mathrm{~mm}$ in largest diameter and 8 $\mathrm{mm}$ in height was noted on the palpebral conjunctiva. It was firm, not tender, and adherent to lid tissue along the full length of its base (Fig. 1).

Neither eye showed a papillary or follicular conjunctival reaction. The right upper lid and both left lids appeared normal. There was no bulbar conjunctival injection or discharge, corneal staining, or anterior segment inflammation in either eye. Rubeosis was present in the left eye. Intraocular pressure was 12 $\mathrm{mmHg}$ in both eyes. Ophthalmoscopic examination disclosed disc neovascularisation, haemorrhages, and exudates in the posterior pole of both eyes.

After the nature and implications of the patient's problems were explained to him we advised excision of the tumour in the right eye and panretinal photocoagulation for the proliferative retinopathy in both eyes. However, the patient refused any treatment. Then on 16 May 1980 he had a sudden loss of vision in the left eye to $6 / 75(20 / 300)$. Gonioscopic examination disclosed that rubeosis in the left eye had become more marked and neovascularisation of the angle at the 9-o'clock position was present in both eyes. A vitreous haemorrhage obscured the view of the fundus 


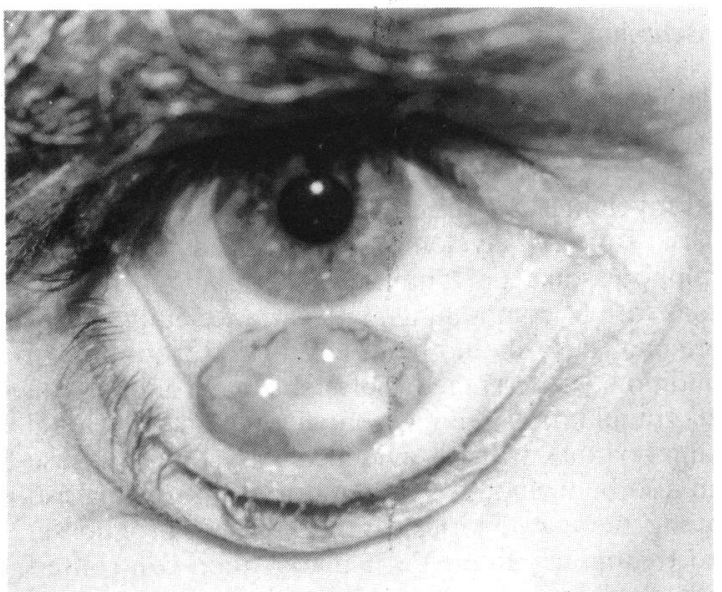

Fig. 1 Discrete tumour with mottled discoloration involving the palpebral conjunctiva of the right lower lid.

in the left eye. The lid tumour appeared unchanged, with no evidence of growth. Because of his failing vision the patient then agreed to enter hospital for ophthalmic treatment.

General physical findings included small ulcers over the pretibial areas bilaterally, absent peripheral pulses, grade $2 / 6$ systolic ejection murmur, and peripheral and ulnar neuropathy. There was no lymphadenopathy. Laboratory tests gave moderately raised fasting blood glucose levels which ranged from 140 to $170 \mathrm{mg} / 100 \mathrm{ml}(7 \cdot 8-9 \cdot 4 \mathrm{mmol} / \mathrm{l})$. The remainder of his laboratory values were normal; these included white blood cell count of $8 \times 10^{9} / 1$ with a normal differential count, a haemoglobin of $14 \cdot 2 \mathrm{~g} / \mathrm{dl}$, haematocrit of $40.0 \%$, normal electrolytes, prothrombin time, partial thromboplastin time, chemistry profile, blood urea nitrogen, creatine, and urine analysis. Total protein measured $7 \cdot 3 \mathrm{~g} / 100 \mathrm{ml}$ $(73 \mathrm{~g} / \mathrm{l})$ with an albumin of $4 \cdot 3 \mathrm{~g} / 100 \mathrm{ml}(43 \mathrm{~g} / \mathrm{l})$. Chest roentgenograms revealed diffuse interstitial markings consistent with early congestive heart failure, which on follow-up roentgenograms had resolved. Electrocardiogram showed normal sinus rhythm and a left bundle branch block.

On 22 May 1980 the patient underwent an excisional biopsy of the lesion of the right lower lid. The most likely diagnosis at this time was a granulomatous nodule, such as a reaction to a foreign body. A scleral graft was placed at the base of the wound. Because of persistent corneal staining the graft was later removed and a conjunctival flap was advanced over the base of the wound.

The tumour was a well circumscribed, oval, pale tan, fleshy mass measuring $15 \times 16 \times 8 \mathrm{~mm}$. Histologically it consisted of sheets of relatively mature plasma cells with characteristic eccentric nuclei and abundant cytoplasm often containing a paranuclear clear space (Golgi space) (Fig. 2). No other cells, such as lymphocytes, histiocytes, or any other type, were present. A Wright-stained touch imprint accentuated the spokewheel configuration of the nuclear chromatin (Fig. 2). Congo red stain for amyloid was negative. Immunoperoxidase staining showed that the plasma cells within the tumour contained cytoplasmic IgM and IgG and lambda light chain only. Electron microscopic examination further confirmed the plasmacytic nature of the neoplastic cells, whose cytoplasm con-

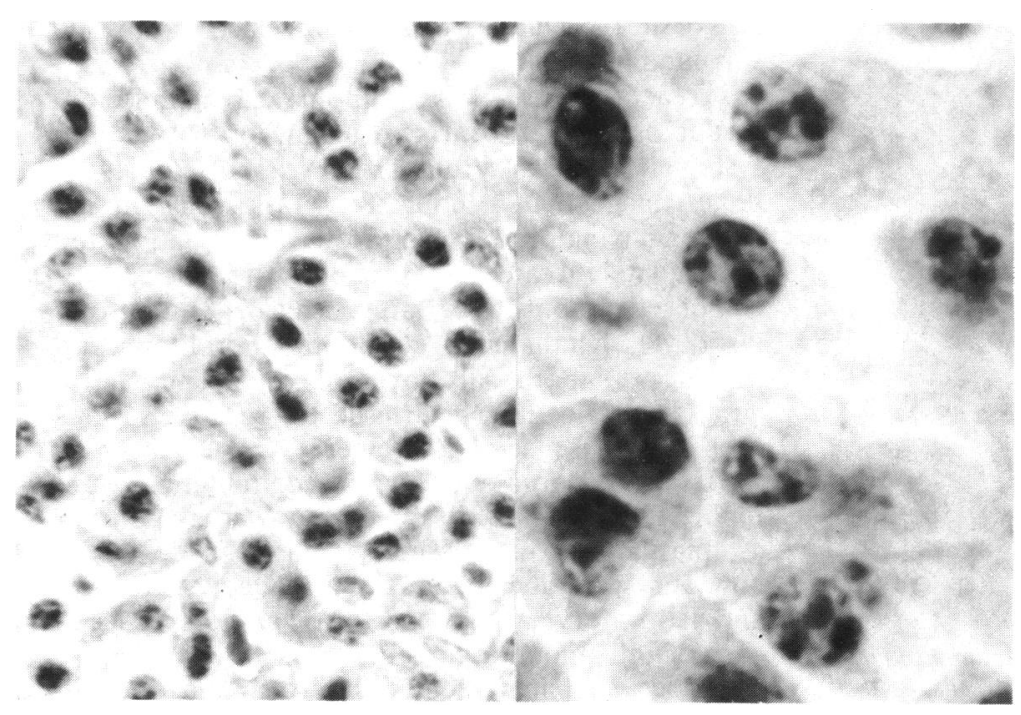

Fig. 2 Left: Plasmacytoma tissue section showing uniform pattern of plasma cells with characteristic eccentric nuclei. (Haematoxylin and eosin, $\times 475$ ). Right: Touch imprint accentuating spokewheel configuration of nuclear chromatin. (Wright stain, $\times 1333$ ). 
tained many parallel strands of rough endoplasmic Discussion reticulum (Fig. 3).

A systemic examination showed no evidence of multiple myeloma. Bone marrow biopsy revealed normocellular bone marrow with no evidence of plasmacytosis. Serum protein electrophoresis was within normal limits, as were the immunoglobin measurements: IgG $1060 \mathrm{mg} / 100 \mathrm{ml}(10 \cdot 6 \mathrm{~g} / \mathrm{l})$ (normal, 700-1500 (7-15 g/l)), IgA $348 \mathrm{mg} / 100 \mathrm{ml}$ (3.5 g/l) (normal, 55-350 (0.5-3.5 g/l)), IgM 257

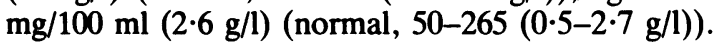
Urine was negative for Bence Jones protein. A bone scan revealed a lesion in the vertex of the skull with more diffuse uptake in the right frontal area. This was consistent with trauma to that area which the patient had sustained several years earlier. Skull roentgenograms, long bone survey, and thoracic and lumbar spine roentgenograms showed no evidence of a lytic lesion. The palpebral conjunctival lesion was therefore classified as an isolated extramedullary plasmacytoma.

During the hospital course the right lower lid healed without complications. The vitreous haemorrhage in the left eye cleared partially and visual acuity improved to 6/15 (20/50). In March 1981 the patient had a sudden loss of vision in the left eye to hand movements. Examination revealed in the left eye a rhegmatogenous retinal detachment with traction; it was repaired by closed vitrectomy and scleral buckling. He is also being followed up in the haematology clinic for evaluation of potential systemic disorders related to the plasmacytoma. In March 1981 his haemoglobin, haematocrit, and serum proteins were within normal limits.

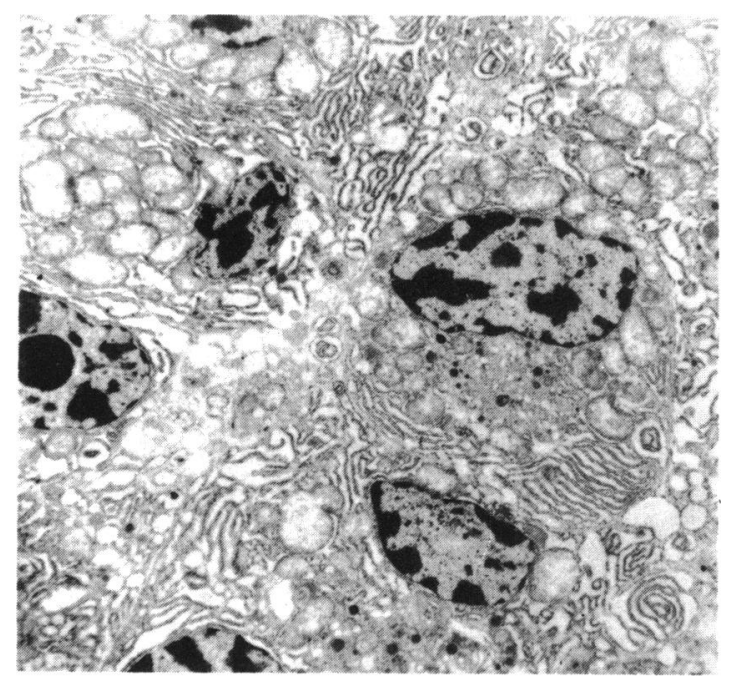

Fig. 3 Electron micrograph showing abundant rough endoplasmic reticulum of neoplastic plasma cells. $(\times 2800)$.

Classification of plasma cell disorders is complex. Azar' has proposed that plasma cell neoplasms be divided into the following categories: multiple plasma cell myeloma, disseminated nonosteolytic myelomatosis, solitary myeloma, plasma cell leukaemia, lymphoplasmacytic lymphomas, malignant lymphomas with $\mathrm{M}$ components, and extraskeletal plasmacytoma. These should be differentiated from benign conditions such as reactive plasmacytoses and plasma cell granulomas. Benign monoclonal and polyclonal gammopathies without evidence of systemic disease can also be included. ${ }^{12}$ It is important to distinguish among these categories, as the causes, prognoses, and treatments differ. Particularly when confronted with a plasma cell tumour of the conjunctiva a distinction among 3 entities should be made: (1) manifestation of systemic multiple myeloma, (2) solitary extramedullary (or extraskeletal) plasmacytoma, and (3) plasma cell granuloma.

Multiple myeloma is a systemic disease associated with plasma cell infiltration of bone marrow and usually osteolytic lesions as well as the presence of a monoclonal immunoglobin in serum and/or urine. These patients commonly have anaemia and bone pain, and there may be associated extraskeletal spread of myeloma.

Solitary extramedullary plasmacytomas arise without evidence of solitary myeloma of bone or multiple myeloma. The bone marrow, urine, serum electrophoresis, and haemoglobin are normal at diagnosis of the localised tumour. Abnormal findings with spread of tumour to soft tissue or bone may develop later, at which point the tumour is no longer an independent solitary lesion..$^{93-15}$ Histologically the tumour consists of sheets of mature plasma cells which may invade surrounding tissue.

A reactive plasma cell granuloma, a benign lesion, is not associated with concurrent or subsequent systemic findings (serum protein abnormalities or bone changes). It is induced by an inciting foreign antigen having produced previous inflammation and is adequately treated by excision. Histologically it is composed not only of mature plasma cells but also of histiocytes, lymphocytes, eosinophils, fibroblasts, and capillary endothelial hyperplasia. The term 'granuloma' has also been used for reactive lesions even in the absence of histiocytes.

Plasma cell tumours of the conjunctiva were reported occasionally in the early twentieth century as 'plasmomas' or 'plasmacytomas.' These cases, however, were documented with inadequate clinical and laboratory evaluations. Most authors believed chronic inflammation to be the cause.$^{1-8}$ In fact most cases occurred in patients with trachoma, and all 
occurred in endemic trachoma regions. In 1915 Verhoeff and Derby reviewed the literature on plasmacytoma and concluded that 'the evidence at hand points to an inflammatory origin for this condition. The clinical fact that it has occurred frequently in conjunctiva showing evidence of existing or previous trachoma points in this direction. ${ }^{7}$ Most later reports of conjunctival 'plasmacytomas' also suggest inflammation as the cause. ${ }^{16-19}$ Most of these lesions would be classified today as plasma cell granulomas. For this reason Dolin and Dewar did not include cases involving the conjunctiva in their review of extramedullary plasmacytomas. ${ }^{20}$

One well documented case involving the conjunctiva resembles a true plasma cell neoplasm that occurred with an orbital mass as a terminal event in a patient with known multiple myeloma. ${ }^{21}$ Jampol and associates described a lymphoplasmacytic tumour of the conjunctiva associated with systemic lymphoma and a monoclonal $\operatorname{IgA}$ gammopathy ${ }^{22}$ Plasma cell infiltration appearing as diffuse thickening of the conjunctiva or conjunctivitis rather than a discrete mass has also been noted. ${ }^{23}{ }^{24}$ In one of these cases a mixed cellular infiltrate was associated with cytoplasmic crystals consisting of IgG. ${ }^{23}$ The other case, according to the authors, ${ }^{24}$ probably represented a reactive chronic inflammatory response rather than neoplasia.

In contrast the patient described here had a fairly well circumscribed mass with no history of ocular inflammation or medical illness. Histopathological examination revealed a lesion consisting of only sheets of mature plasma cells without a mixed cellular population and no fibrovascular proliferation. The finding of only lambda light chain on immunoperoxidase staining supported the diagnosis of neoplasia. The presence of more than one heavy chain, as in our case, has been reported in rare cases of myeloma. ${ }^{25}$ Clinical, haematological, biochemical, and radiological investigations ruled out systemic disease. This lesion therefore meets the diagnostic criteria for a true solitary extramedullary plasmacytoma of the conjunctiva. Long-term stability of both symptoms and myeloma protein production may occur in patients with indolent myeloma and in those with localised plasmacytoma.$^{26}$ The long history of the lid lesion which remained localised in our case is therefore not inconsistent with the diagnosis of plasmacytoma.

Solitary extramedullary plasmacytoma of the orbit, as of the conjunctiva, occurs rarely. ${ }^{27}$ Somewhat more common are plasma cell pseudotumours ${ }^{28}$ and orbital plasma cell tumours which represent an extraskeletal manifestation of multiple myeloma ${ }^{28-30}$ In the latter category in 23 of the 30 patients studied by Rodman and Font proptosis was the initial manifestation of the disease. ${ }^{28}$
The diagnosis of plasmacytoma rather than plasma cell granuloma is liberally applied to a number of plasmacytic growths at other sites. $80 \%$ of the reported 'extramedullary plasmacytomas' develop in the oral cavity or respiratory tract. ${ }^{31}$ Some of these, however, may be benign inflammatory processes even though they appear as a discrete mass. ${ }^{9}$ Following in frequency are plasmacytomas involving the gastrointestinal tract and lymph nodes. ${ }^{152}$ Skin and soft tissue are more rarely involved..$^{33}$

Not only do the causes differ but prognosis and treatment of plasma cell disorders also vary. Unlike reactive plasma cell granuloma, extramedullary plasmacytoma is considered to be of low-grade malignancy, and the clinical course after excision is not entirely benign. Studies of nonocular cases have shown that multiple myeloma may develop after several months or even years in up to $30 \%$ of cases. ${ }^{34}{ }^{35}$ Involvement of lymph nodes and development of new foci of tumour cells in soft tissue and bone can occur. ${ }^{134}$ Treatment for both plasmacytoma and plasma cell granuloma consists of excision, but radiotherapy is recommended in addition for the neoplastic growth. ${ }^{36}$ Although no such cases have been reported, it is conceivable that patients with extraskeletal plasmacytoma of the conjunctiva may also subsequently develop systemic manifestations of multiple myeloma. Therefore periodic systemic evaluation is warranted. We decided to follow up our patient closely after complete excision of the tumour rather than to treat him with radiotherapy.

We thank Ingrid von Saltza for help with translations.

\section{References}

1 Pascheff C. Plasmacellulare Bildungen (Plasmomen) der Bindehaut und der Hornhaut. Albrecht von Graefes Arch Klin Ophthalmol 1908; 68: 114-25.

2 Pascheff $C$. Weitere Mitteilungen über die plasmacellularen Bildungen der Bindehaut-conjunctivitis plasmacellularis. Albrecht von Graefes Arch Klin Ophthalmol 1909: 71: 569-72.

3 Baurmann M. Über das Plasmom der Conjunctiva und seine Beziehung zum Amvloid. Albrecht von Graefes Arch Klin Ophthalmol 1922; 109: 236-51.

4 Kreibig W. Über die Plasmocytome der Bindehaut. Albrecht von Graefes Arch Klin Ophthalmol 1933; 131: 89-101

5 Rados A. Über Plasmome der Bindehaut. Z Augenheilkd 1913; 29: $125-34$.

6 Hoffman W. Ein Beitrag zur Plasmomfrage. Z Augenheilkd 1925; 55: $164-80$

7 Verhoeff FH. Derby GS. Plasmoma of the lacrimal sac. Arch Ophthalmol 1915; 44: 252-64.

8 Hellwig CA. Extramedullary plasma cell tumors as observed in various locations. Arch Pathol 1943; 36: 95-111.

9 Azar HA. Pathology of multiple myeloma and related growths. In: Azar HA. Potter M. eds. Multiple Myeloma and Related Disorders. New York: Harper and Row, 1973; 1:2-26.

10) Bahadori M. Liebow AA. Plasma cell granulomas of the lung. Cancer 1973; 31: 191-208.

$11 \mathrm{Fu}$ YS. Perzin KH. Nonepithelial tumors of the nasal cavity, paranasal sinuses and nasopharynx. A clinicopathologic study. IX. Plasmacytomas. Cancer 1978; 42: 2399-406. 
12 Kyle RA. Monoclonal gammopathy of undetermined significance. Natural history in 241 cases. Am J Med 1978; 64: 814-26.

13 Wiltshaw $E$. The natural history of extramedullary plasmacytoma and its relation to solitary myeloma of bone and myelomatosis. Medicine 1976; 55: 217-38.

14 Conklin R. Alexanian R. Clinical classification of plasma cell myeloma. Arch Intern Med 1975; 135: 139-43.

15 Nelson MG, Lyons AR. Plasmacytoma of lymph glands. Cancer 1957; 10: 1275-80.

16 Mathur SP. Conjunctival plasmoma. Br J Ophthalmol 1959; 43: 499-500.

17 Abboud I. Plasmoma of the bulbar conjunctiva. Bull Ophthalmol Soc Egypt 1962; 55: 29-32.

18 Dayal Y, Agarwal PK, Agarwal LP. Plasmocytoma of the palpebral conjunctiva. Orient Arch Ophthalmol 1964; 2: 40-1.

19 Bhargava S, Gupta MC. Vyas K. Saxena BP. Solitary plasmocytoma of conjunctiva. J All-India Ophthalmol Soc 1967; 15: $38-9$.

20 Dolin S, Dewar JP. Extramedullary plasmacytoma. Am J Pathol 1956; 32: 83-103.

21 Benjamin I, Taylor H, Spindler J. Orbital and conjunctival involvement in multiple myeloma. Report of a case. Am J Clin Pathol 1975; 63: 811-7.

22 Jampol LM, Marsh JC. Albert DM. Zimmerman LE. IgA associated lymphoplasmacytic tumor involving the conjunctiva. eyelid and orbit. Am J Ophthalmol 1975; 79: 279-84.

23 Rao NA, Font RL. Plasmacytic conjunctivitis with crystalline inclusions. Arch Ophthalmol 1980; 98: 836-41.

24 Yee RD, Savage DD, Cogan DG, Nienhuis AW, Minna JD. Plasma cell infiltration of the conjunctiva associated with pan- cytopenia, dermatitis, and polyclonal gammopathy. Am J Ophthalmol 1976; 82: 486-91.

25 Taylor CR, Russell R. Chandor S. An immunohistologic study of multiple myeloma and related conditions, using an immunoperoxidase method. Am J Clin Pathol 1978; 70: 612-22.

26 Alexanian R. Plasma cell neoplasms. CA 1976; 26: 38-49.

27 Cogan JF. Extramedullary plasmocytoma of the orbit. $\mathrm{Br} J$ Ophthalmol 1956; 40: 681-5.

28 Rodman HI, Font RL. Orbital involvement in multiple myeloma. Arch Ophthalmol 1972; 87: 30-5.

29 Mewis-Levin L, Garcia CA, Olson JD. Plasma cell myeloma of the orbit. Ann Ophthalmol 1981; 13: 477-81.

30 Clarke E. Plasma cell myeloma of the orbit. Br J Ophthalmol 1953; 37: 543-54.

31 Pahor AL. Extramedullary plasmacytoma of the head and neck. parotid and submandibular salivary glands. J Laryngol Otol 1977; 91: $241-58$.

32 Remigio PA, Klaum A. Extramedullary plasmacytoma of stomach. Cancer 1971; 27: 562-8.

33 Canlas MS, Dillon ML, Loughrin JJ. Primary cutaneous plasmacytoma. Report of a case and review of the literature. Arch Dermatol 1979; 115: 722-4.

34 Corwin J, Lindberg RD. Solitary plasmacytoma of bone vs. extramedullary plasmacytoma and their relationship to multiple myeloma. Cancer 1979; 43: 1007-13.

35 Todd ID. Treatment of solitary plasmacytoma. Clin Radiol 1965; 16: 395-9.

36 Woodruff RK. Whittle JM. Malpas JS. Solitary plasmacytoma. I. Extramedullary soft tissue plasmacytoma. Cancer 1979; 43: 2340-3. 